\title{
The role of medical humanities, ethical coaching and global bioethics in addressing the ethical vulnerability of health care practitioners
}

NGTT DEEL 55, NR 3 \& 4, 2014

\section{Lategan, Laetus}

Central University of Technology, Free State

\begin{abstract}
This paper outlines the many ethical challenges faced today by health care practitioners. These challenges are not limited to the conventional bioethical challenges of life and death, informed consent, palliative care or research on human subjects only. The literature review suggests that complex matters such as a weakening health care system, health care research supported by the medical industry, socio-economic and sociopolitical circumstances, communication, and the globalization of bioethics contribute to the already numerous ethical challenges that presently intensify the ethical vulnerability of health care practitioners. Given this context, the aim of this paper is to unpack what the ethical challenges as experienced by health care practitioners entail and how health care practitioners can be supported to deal with these challenges. Aspects such as the medical humanities, ethical coaching and an integrated bioethical model to support health care practitioners are discussed. Ultimately, the discourse is based on the values of Christian ethics.
\end{abstract}

\section{KEYWORDS}

Health care practitioners, Ethical coaching, Medical humanities, Bioethics, Christian ethics

\section{TREFWOORDE}

Gesondheidsorgwerkers, Etiese opleiding, Mediese menswetenskappe, Mediese etiek, Christelike etiek

\section{CONTACT DETAILS}

Prof Laetus Lategan

llategan@cut.ac.za 


\section{THE COMPLEXITY OF HEALTH CARE}

A growing body of knowledge on the subject of health care ethics suggests that more attention should be afforded to the ethical vulnerability of health care practitioners. Vanlaere and Burggraeve (2013) as well as Phalime (2014) made it clear that health care practitioners (traditionally referred to as white coat workers to symbolize their purity) need active ethical support and guidance to exercise their duties. A major reason for this is that ethical issues can no longer be limited to the patient only. This is due to the reality that the health care profession is influenced by the medical industry as well as national and international health care policies that challenge the quadruple relationship between health care practitioners, the patient, government and business and industry (Ten Have, 2011). A number of examples illustrate the complexity of these challenges. Avorn (2013) linked the "voluminous evidence about the clinical choices" physicians face every day to the Stendhal Syndrome. The original meaning of the Stendhal Syndrome refers to a psychosomatic reaction, which manifests as an overwhelming feeling that one may experience as a result of the lavishness of art. ${ }^{1}$ The significance of this comparison lies therein that it underlines the given that health care practitioners are experiencing one too many professional and personal challenges on a daily basis. Woolf (2012) added yet another example in arguing that there are false expectations of what medicine can do. Very often these expectations create tension between what is and what is not possible. Due to unwarranted expectations, health care practitioners, policy makers and patients may be at conflict in their expectations regarding what health care can deliver. Roberts (2012) likewise contributed to the discussion on bioethics and health disparities. She indicated that there is a long history of employing biological definitions to make social inequities seem natural instead of blaming them on societal injustice. It is also evident that race-neutral economics and race-specific genetics contribute towards health care disparities. Socio-economic circumstances are also contributing to health status. To combat health disparities, individual and institutional bias should be eliminated.

The emerging discussion in this paper is based on recent studies by Ten Have (2011), Phalime (2014) and Vanlaere and Burggraeve (2013) who outlined the many ethical challenges health care practitioners are facing. These challenges relate to many more issues than the choice between life and death, informed consent, palliative care, the doctor-patient relationship and patient privacy. Ten Have, Phalime as well

1 Marie-Henri Beyle, a French author known by the pen name Stendhal, visited Florence in 1817. Seeing all the art was an overwhelming experience. Graziella Magherini, an Italian psychiatrist, later coined the term Stendhal Syndrome to capture this overwhelming feeling that one may experience in response to art (Avorn, 2013). 
as Vanlaere and Burggraeve share the opinion that current health care necessitates attention regarding the vulnerability of health care practitioners and how best their ethical needs can be entertained or attended too.

\section{ORIENTATION OF PAPER}

The aim of this paper is to offer a contribution to the debate on how to care for health care practitioners in the context of globalized bioethics. Bioethics is truly global in nature and multidisciplinary in approach since its application is not limited to one country or system only and solutions are sought from many disciplines to find a proper solution to a given problem (Ten Have, 2011).

This paper is a literature-informed study on the ethical support of health care workers. The paper is furthermore consciously based on Christian ethics. The view on Christian ethics is informed by Douma's (1999) comment that in Christian ethics it is not about selecting themes, but rather presenting a contribution from a specific perspective. In Christian ethics contributions are made from the Scripture and Church Confessions. The perspectives of Koopman and Vosloo (2002) will namely inform the application of Christian ethics in this paper. According to the aforementioned authors, Christian ethics is a relational ethics. In this ethical orientation an ethic of responsibility is important. The responsibility is firstly devoted to Christ (see for example Matthew 25:31-36). This responsibility relates to the coram Deo. Hence an orientation of a lifestyle towards the kingdom is required. An ethic of responsibility has a number of characteristics. The most notable of these characteristics are to get people involved (active instead of apathetic), to comprehend the consequences of people's unethical behaviour, to respond (in actions and words) to ethical misconduct and to have a vision for the future (hope). The advantage of an ethic of responsibility is that it supersedes individual disposition that is individually driven and individually orientated. The importance of Koopman and Vosloo's perspectives is that these authors (i) frame ethics in the context of a specific lifestyle and relation, (ii) their views call on both the individual and the community to support each other in securing an ethical culture, and (iii) ethics is always linked to action (what you can do) and hope (one does not live for this situation only).

In this paper a definitive paradigmatic choice is at work. What is proposed is an ethical view that goes beyond the conventional understanding of ethics, namely that it is more than merely a choice between what is right or wrong, good or bad. Ethics is all about normative or value-driven behaviour and decision-making. This behaviour and decision-making are aimed at promoting the common good of society. In this paper a number of normative perspectives will namely contribute towards the debate 
on the how to support health care practitioners in dealing with their respective ethical challenges.

Although I am mindful of, for example, Ozawa-de Silva, Dodson-Lavelle, Raison and Negi's (2012) comments that happiness and well-being for oneself and one's loved ones are a universal value despite all the cultural and religious differences that may exist, there is no reason why specifically Christian ethics cannot be useful in or make a contribution to this discussion. Even though Ozawa-de Silva et al. (2012:158) argue in favour of what they call the need for "secular ethics" to avoid partiality of one religious tradition over another and correctly remarked that " $t \mathrm{t}]$ he question of ethics will always be central to religious tradition," a specific view can nonetheless not be disregarded. It is here that I appreciate Schotsmans' (2012) argument that it is not about the scope of the contribution, but rather the value and completeness it can add to a particular topic. What he advocates is the value a particular orientation can make instead of the public support such an orientation may enjoy.

The views promoted in this section of the paper will serve as a framework to contribute towards the ethical support of health care practitioners.

\section{ETHICAL CHALLENGES IN HEALTH CARE}

Given the challenges in global health care, the following question can rightly be asked: How should we support health care practitioners in dealing with their ethical challenges? The question seems to not elicit an obvious answer. The medical profession frequently considers what kind of ethical behaviour should be exercised by health care practitioners, but their ethical preparedness or training is ever so often neglected or undervalued.

The ethical support of health care practitioners is informed by three different observations.

- Vulnerability in health care goes beyond patients' health conditions. Personal safety and security, finance, aging and the reality of death are but a few of the challenges contributing to people's vulnerability. Political developments and economic growth impact on vulnerability too. Typical examples include the alleged mismanagement of public health care in general, the availability of beds and medicine, the rising cost of health care as well as poor communication due to different languages being spoken among community members.

- A replacement culture is apparent in health care: if something is not good enough, then it must be replaced. This attitude is often subscribed to by bioengineering and plastic surgery. The primary motive for health care here is 
not healing but substitution. This substitution, however, does not come without emotional cost.

- Technology in health care is important but not obvious. In a world characterized by unevenness of access to technology, the utilization of technology in health care can be quite intimidating. Consider, for example, the influence of telemedicine on a patient not familiar with (communication) technology or a computed tomography (CAT) scan on a patient who has never been exposed to (medical) technology before.

To simply rely on the "Oaths" (inter alia Hippocrates, Helsinki, Nuremberg, American Medical Association) may not be enough when ethical support for health care practitioners is considered. Although common themes in these Oaths are (i) the focus on patients and how health care practitioners should treat them, (ii) the principle that the patient is a subject (i.e. a person) and not an object, (iii) the tenet that a professional attitude should prevail at all times, and (iv) the view that the first dictum should always be "do no harm", a literature survey suggests that this simply may not be enough. Health care ethics is traditionally based on four principles: respect for individuals and their autonomy, non-maleficence, beneficence and justice (see for example Mueller, Hook \& Fleming, 2004:554). Ten Have (2011:27) commented that these very well known, highly effective and almost sacred principles are commonly referred to as the "Georgetown mantra" because of the association Georgetown scientists has with the usefulness of these principles. A concern, however, is that there is very little focus on the community - except for social justice. An orientation on the community and the society is evidently lacking. In dealing with the ethical care of health care workers, the role of the community or society cannot be overlooked. Communities and societies expect health care practitioners to care and to cure (i.e. to improve quality of life and living), but it is the very same communities and societies that often contribute to the ethical vulnerability of health care practitioners because of the frequently challenging demands directed at the aforementioned practitioners.

An appropriate example can be taken from Rozmaryn's (2011) discussion of the guidelines for hand care professionals - a major issue in American military medicine due to offshore conflicts. The importance of treatment (during and following hand surgery) is the hope it brings to especially war victims. However, this hope is not realized without its challenges. The challenge with this type of surgery is compartmentalization and the lessening of doctors' involvement in their patients' care. It is against this background that Rozmaryn raises questions such as: How must medical education adapt to teach ethical values? And how should medical societies promote the teaching and enforcing of ethical codes? He commented in saying that 
"[ $t$ ]oday's clinicians are buffered by many forces that have a direct impact on their ability to deliver quality ethical care" (Rozmaryn, 2011:1402).

The challenge is deepened due to the humanity aspect associated with health care. A perspective that cannot be set aside is that in health care treatment it is very often about caring and healing the "other." It so happens that the "other" is often unknown or unfamiliar. It is therefore a necessity that health care workers should be mindful of a number of aspects such as language, culture, gender, race, poverty, discrimination and health care status. This knowledge basis is further challenged by developments such as the influence of the Internet, which eroded the perspective that "doctors know best" and which allowed patients "to play doctor" (see Rozmaryn, 2011:1397).

It is in the context of the "other" that Burggraeve (2000) and Ozawa-de Silva et al. (2012) challenged the anticipated common understanding of ethics. Burggraeve shaped Emmanuel Levinas' views of the "other" in his (Burggraeve's) ethical discourse. The other is the person with whom one is crossing paths unplanned. It is spontaneous and intended to engage with other people. This engagement is frequently compromised because of the absence of ethics. Engagement with the other also necessitates that one is available for unfamiliar or foreign people. Applied to the discussion in this paper, it entails that health care practitioners should care for their patients through their behaviour, commitment, attitude and specialized knowledge. In return patients should also be approachable and allow health care practitioners to enter their personal space. Ozawa-de Silva et al. (2012:147) wholly support this approach to ethics. They argue that ethics should be broadly understood as "a way of conceptualizing how human beings relate to one another and their environment with specific regard to suffering and its alleviation." This perspective is offered against the reality that ethical values are fundamental for each society but that it cannot merely depend on legal, political or economic systems or even the reform of such systems. Ethics, ultimately, need to be imbedded in people's personal orientation and attitude.

Led by these arguments, a case can therefore be presented that ethical training simply cannot be avoided. The questions raised by, for example, Thies (1998:153-154), Smit (2000) and Ten Have (2011) are therefore appropriate, and these questions pertain to why ethics should form part of the curriculum.

Thies (1998:153) made two observations in support of his question: He firstly argued that ethics and critical thinking skills necessary to tackle arduous moral problems should be an essential part of higher education and, secondly, that students should also be educated in the ethical nature of decision-making. 
Smit (2000) echoed the same sentiments. He remarked that ethics in the curriculum has three advantages: (i) it promotes humanity, (ii) it counteracts reductionism, and (iii) it promotes social responsibility. Of importance is his comment that ethics is not about rationality, but an integrated normative framework in each person's behaviour. It is here that applied ethics has an important role to play: "It relates to the question how we should concretize our compassion for human beings and their environment in the problematic situations of life" (Smit, 2000:150). Typical norms for bioethics are compassion, care, commitment, service, self-sacrifice, reverence for life and respect for personhood (Smit, 2000:150).

Ten Have (2011:79) reminded the health care profession that one cannot "make" people ethical, but one can nevertheless educate and sensitize them to be ethical and prepare them to be responsive to ethical challenges. One should never underestimate the value that knowledge can add when a person is introduced to a potential ethical problem and when it comes to affording alternatives in how to deal with such a problem.

The totality of Thies, Smit, and Ten Have's arguments is well captured by Gabriele (2011a) who is very articulated on this matter. He stated that all disciplines are required to have a complete view of patient-centred care. Ethics training is to optimize the good and not to combat the evil/bad (see Gabriele, 2011b). Such a view is also expressed in the aforementioned study by Vanlaere and Burggraeve (2013) and in which they claim that health care practitioners should be ethical at all times although their unethical behaviour may occasionally be seen as ethical protest (as a last resort) against all the challenges that they may encounter.

The question now remains: How can a community support health care practitioners with their ethical challenges?

A number of observations can be posited to answer this question. Firstly, the complexity of ethical challenges beyond the traditional scope of bioethics should be unpacked. Context will give meaning to why and how ethical support should be optimized for health care practitioners. Secondly, can a global understanding of bioethics and paradigm shifts in ethics assist with the comprehension of the complexity of (primary) health care in a health care economy challenged by a human rights culture? Thirdly, is ethics a science in its own right, which influences scientific discourse? Ethics is warranted in medical education, medical research and the practice of medicine too.

In the next section these observations will be unpacked to inform the kind of ethical support that should be extended to health care practitioners. 


\section{BIOETHICS - CONCEPTUAL HARMONY OR ADVANTAGE OF DIVERSITY?}

In his discussion on bioethics, Ten Have (2011) draws attention to the given that different countries attach different meanings to what bioethics entails. In North America and Western Europe, bioethics relates to life sciences, medicine and health care. This understanding is informed by especially technical development in the application of health care. Gene therapy, reproductive medicine and organ transplantation are examples of technical developments. In Latin America, however, bioethics is more related to the socio-political context than the development of science and technology. Latin-American countries are known for their socio-economic problems. Medicine is seen as one way of bridging the divide between those who have (i.e. the privileged) and those who do not have (the underprivileged). In most cases science, technology and medicine are in the service of those with power and money. Here is the challenge for bioethics to bring justice and equality to society. In Asia - where the focus is on man, his community, society, and nature - bioethics has to serve the community instead of the individual. The matter is further complicated by the influence of different religious systems and confessions on bioethics.

These comments, however, are more than mere observations. These comments, namely, have a fundamental influence on the application of bioethics in health care. Bioethics is no longer about patient care only. Bioethics speaks essentially to three challenges in health care. These challenges are:

- The socio-economic and socio-political context in which health care is practised: In emerging economies primary health care is a priority. The challenge is that what is typically associated with primary health care, namely access to clinics, medicine, basic therapies, hygiene and palliative care, is often absent. The bioethical concern then is not what is right or wrong (as a general thesis for ethics), but rather the absence of primary health care that is directly related to a human rights culture and the Constitution.

- The role of health care on economic development: It is often commented that health care has become an economy in its own right. Not only has the cost of health care skyrocketed, but also its sophisticated therapies are either available to the wealthy only or are practised for monetary gain.

- The influence of and response to science, technology and research on bioethics: The ethical question whether doctors/medical researchers/health care practitioners can do what they are able to do, is not new. The view that science can empower health care practitioners to do whatever they wish to do 
is commonly known. But it is these distorted power relations ("gods over life") that often cause insecurity in the health care/patient relationship.

Ten Have (2011:23) is justified in asking whether universality cannot be found despite all the diversity. His question is hinting at possible communalities in the application of bioethics in health care. In my view one needs to comprehend the paradigm shifts in health care and the challenges associated with health care to effectively apply a global bioethics to ethical dilemmas. A number of paradigm shifts can be identified within bioethics. The following shifts are noteworthy:

- The presence of ethics is seen as a key to a "healthy" society. Major developments such as the Universal Declaration of Human Rights (1948) and major ethical codes such as Hippocrates, Helsinki, Nuremberg and the American Medical Association suggest that ethics is no longer about the proverbial "good" and "bad" only, but more about the value it can bring to the public good of society. It is a common belief that bioethics can assist with the rolling-out of primary health care to communities.

- Ethics has become less dependent on religion and more based on a human rights culture. There is a growing opinion that ethics should be more informed by a human rights culture and that it (ethics) should be freed from religion. This view is not inspired or dictated by whether people believe or not, but rather based on the view that ethics should follow in the footsteps of the sciences - namely to disconnect religion and ethics. Burnet (2005) differs from this point of view. He argued that after $9 / 11$ one couldn't avoid considering questions of spirituality. Secularism is itself an ideology that is being questioned by postmodern analysis. This necessitates a post-secularist thinking that requires respectful debate between varieties of interpretations, which go beyond mere personal belief.

- The view exists that ethics is more about linking up with "big" issues such as corruption, the decline of services, the need for integrity, compassion, respect, responsibility and involvement and less with individual morality (personal choice). The "group's" opinion now overshadows the "individual's" orientation.

- Ethics in health care is influenced by the "medical economy." Capitalism and economic challenges contributed to new ethical challenges. This shift ranges from the designer baby (as a result of genetic engineering) to the (dis) advantages telemedicine can hold for a society. Care has henceforth taken on an economic interpretation instead of one of compassion and service.

These paradigm shifts call for medical humanities that can reflect the ethical values required for health care practitioners to deal with bioethical challenges. The 
identification and application of these values are markers in the drive to support health care practitioners with their ethical challenges.

\section{ONCE AGAIN: MEDICAL HUMANITIES AND ETHICAL COACHING AS ETHICAL SUPPORT}

Bleakley, Broemer and Marshall $(2005: 3,4)$ advocated the importance of medical humanities in medical education - not as an elective but as a core. They are also of the opinion that it should not merely be yet another curriculum, but that it should be informed by aesthetics, imaginations and engagements with the ethical aspects of medical practice. They viewed the primary justification of such a course as to educate for empathy. Humanities education will sensitize medical students to have a deeper understanding of their future profession's moral implications. Hence are medical humanities not only about a human side to compensate for an overdose of a technical rational curriculum, but a different look at educating future health care practitioners. It is in this context that Bornstein (2013) promoted the necessity to support doctors and medical students to reconnect to the meaning of their work and to stay committed to it. He argued that deriving meaning from one's work could transform the working experience.

This observation is not made in passing. Media reports on the state of health care in South Africa are alarming. The comments cover challenges such as dysfunctional hospitals, corruption, the insufficient availability of basic medicines and demotivated staff. Following from these comments is the challenge how an ethical climate can prevail in the absence of ethical values. Ten Have (2011:209) argued in favour of scientific integrity, welfare of patients and quality of education as the standard for health care. But, in the apparent absence thereof, I am advocating ethical coaching for health care practitioners.

The coaching I am advancing covers four ethical categories in support of a bioethics culture. These categories are: (1) research ethics and integrity, (2) professional and work ethics, (3) organizational ethics and (4) personal ethics. The following contents can be offered in support of an enabling and supportive bioethics culture.

\subsection{Research ethics and integrity}

Ten Have (2011) is justified in his observation that science cannot function without ethical values. Health care depends on scientific and technological developments and therefore research ethics and integrity will play a leading role in health care. Many challenges exist in health care, most notably respect for human life and its vulnerability, research on human subjects and the role of pharmaceutical companies 
in health care research. These and many more challenges are a proverbial runaway train that can very easily derail a constructive bioethics culture. Research ethics and integrity should therefore not be neglected in building a bioethics culture. There are simply too many examples of scientific misconduct in bioethics to ignore the importance of research ethics and integrity.

Kornfeld (2013) as well as Godecharle, Nemery and Dierickx (2013) provide interesting perspectives on ethics training in research ethics and integrity. Kornfeld based his perspective on his experience with scientific integrity. He argues that novice researchers are guilty of scientific misconduct because of their fear of failure. For established researchers it is the enticement of academic and/or financial awards causing scientific misconduct. His opinion is that the following issues should be addressed: reduce the fear factor for young researchers and increase the fear of detection in the established researcher. It is envisaged that mentorship can address this challenge. On the same topic Godecharle et al. proposed better strategies and a culture of integrity. The lesson to be taken away from their comments is the importance of a supportive and enabling environment to do health care research in. Nobody needs to be reminded that value-driven science is one of the pillars of quality health care.

\subsection{Professional and work ethics}

Professional ethics captures the notion of how workers should behave ethically in the workplace (Shaw \& Barry, 2004:8-9). Although ethical codes play an important role in guiding ethical behaviour in the workplace, it is no guarantee that ethical behaviour will prevail at all times (Robbins, Bergman, Stagg \& Coulter, 2003:158). It is henceforth a matter of continuous education, setting a good example, and leadership. The employer, however, has a self-commitment to be ethical in the workplace as well (Shaw \& Barry, 2004:9). Work ethics relates to those values associated with the work that one is doing and also the performance as a result of the work. For Lenn (2002) there are some critical questions to be asked in work ethics. Important for this study is one's own views of the role of work in one's life, the type of work one is doing and what kind of organization one would like to work for. All these questions relate to the values one holds and how these values are reflected in one's labour. To me it is important that regardless the type of work that one does, one should add value to the workplace and work itself. These values are based on the individual's value system and the influence of the workplace on an individual's value system.

In the context of the health care profession, Mueller et al (2004:560) suggested a review of four topics when ethical dilemmas are considered: medical indications, 
patient preferences, quality of life, and contextual features. The purpose is to gain a comprehensive view of the matters in hand. Without having a good understanding of the complexity of ethical challenges, the concern is that an uninformed opinion can result in what is commonly known as "Fred Flintstone" ethics. This can be true in cases where health care practitioners may not be familiar with new medical conditions such as moral injury (especially as regards military and war veterans), the care for geriatric patients (because of the global aging of populations) or the impact of industry-led medical research (especially due to the huge investments made by global pharmaceutical companies).

\subsection{Organizational ethics}

Hospitals and clinics form the basis for health care. As part of an organizational structure it is important that these facilities create an enabling and sustainable environment. In order to do so, the concept of "health care citizenship" can assist to uphold organizational ethics. Health care citizenship is copycatted or replicated from the business concept of "corporate citizenship." This concept presupposes that the organization is comparable with a (democratic) country. As each citizen has the responsibility to live up to the constitution of the country and its democratic values, a similar responsibility is expected from corporates. In addition, corporate citizenship workers are also reliant on each other - this fosters a spirit of mutual support, a sense of belonging, ownership and active participation (Robbins et al [2003:159]; Crane \& Matten, 2004:61-70). In juxtapositioning health care citizenship with corporate citizenship, bioethical values can be promoted as a common standard that each health care practitioner should subscribe to.

It is in this context that Robbins et al (2003:60-61) are promoting workplace spirituality. This concept refers to how the working environment can contribute towards adding meaning to one's life.

\subsection{Personal ethics}

One of the purposes of a personal ethic is to promote compassionate ethics. Taboada (2011) has a defined view of compassionate ethics. She argues that a compassionate response can be authentic only when the subject takes the "free decision to do actually everything that is in his/her power to overcome or alleviate this other person's suffering". In practice this means that after being emotionally and cognitively 'moved' by another person's suffering, one have to 'move' oneself in concrete acts. This requires self-commitment and then action. The importance of compassion is 
well emphasized by Ozawa-de Silva et al (2012) who argued that it is an ethical value in its own right and should be promoted in the foundations of personal ethics.

\subsection{An integrated bioethics model}

Ethics is fundamentally about ethos - the fundamental character of individuals and institutions. Ethics has to do with value systems, interdisciplinary engagements to discover the greatest good and the identity and character of individuals and as a society as a whole. The above-mentioned perspectives can be combined into an integrated bioethics model. This model can be graphically presented through the radical centres image. This image emphasizes the relationship to a central idea.

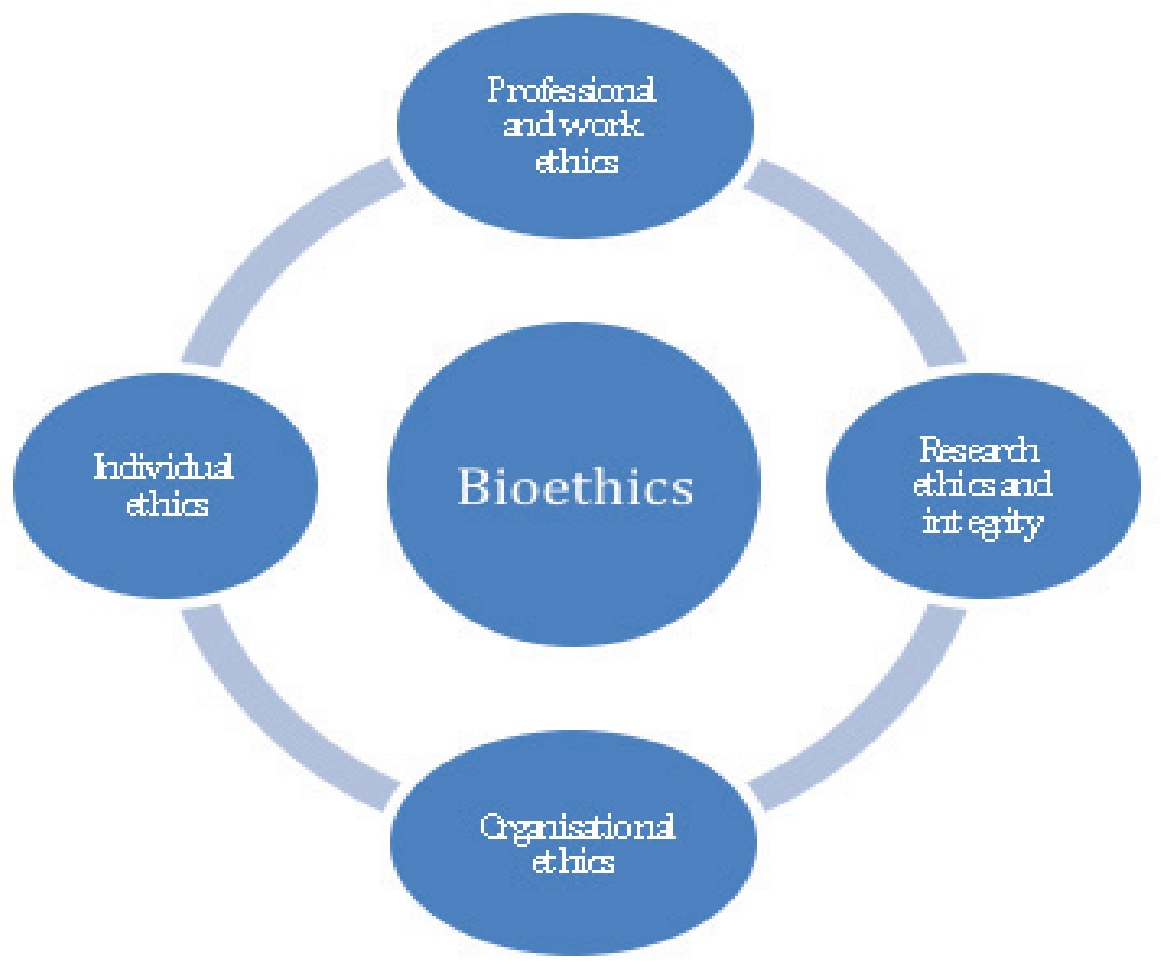

\section{SUMMATIVE PERSPECTIVE}

A number of perspectives have been developed in this paper that can be purposeful for the debate on how to support health care practitioners in coping with their ethical challenges. Throughout the paper it was suggested that a global understanding of bioethics, the medical humanities and ethical coaching could add to the framework in dealing with health care practitioners' vulnerability. The following perspectives can be presented in dealing with this vulnerability: 
A leading attribute in health care is to value humanity, to be sensitive to vulnerability, to avoid harm at all times and to protect life during all stages (from conception to old age). This calls for care, mercy and justice - not only for the patient, but also for the health care worker. Care and mercy also imply an underlying power relationship. Since these attributes are primarily performed by health care practitioners, ethical coaching should guide them to not misuse this position of power and trust. The misuse of any power or trust relationship puts the health care practitioner at risk and will add to a distorted relationship between colleagues and patients. This will increase the ethical vulnerability of the health care practitioner who has challenged the ethos of ethics - namely relationships. It is here where organizational climate and workplace spirituality should create a secure working environment. Health care practitioners cannot perform any of these actions if they do not experience these values in return.

The Christian ethics framework subscribed to in this paper reminds us that the relationship with the other and the way in which the other awakens us, is fundamental to Christian ethics. Regardless of the level of familiarity with the other, a Christian ethic will promote the dictum to care of the other, as one would take care of oneself. A Christian ethic will remind the health care practitioner to take responsibility for the other. This responsibility is rooted in man's central calling to neighbourly love, to be engaged with the other and to bring value and meaning to the life of others. The Biblical parable of the merciful Samaritan (Lk 10:30-37) portrays that the unknown person in need requires one's sincere and compassionate attention. The Samaritan, unlike other travellers who came upon a severely injured man at the side of the road, did not simply pass by and did not neglect to offer his assistance. It furthermore requires an extension of oneself (the Samaritan took the injured man to a boarding house). It necessitates, in addition, that one should not avoid the other after rendering assistance, but that one should be willing to repeat one's kindness (the Samaritan vowed to return to the injured man).

Health care is not about healing only, but also to connect people (engagement). Health care is, in addition, a bridge between anxiety (because of illness) and hope (there may be a future for me). It is proposed that ethical coaching should bring this reality to health care practitioners too. 


\section{LITERATURE}

Avorn, J 2013. Healing the overwhelmed physician, The New York Times, 11 June.

Bleakley, A, Broemer, R, Marshall, R 2005. 'Have a nice day!' - Potential abuses of the moral invitation in medical humanities education. Paper read at the Discourse, Power, Resistance Conference 4. 21-23 March 2005. University of Plymouth. 3-4.

Bornstein, D 2013. Who will heal the doctors? The New York Times, 2 October.

Burggraeve, R 2000. Eigen-wijze liefde: fragmenten van bijbels denken. Leuven: Acco.

Burnet, J. Talking about spirituality in the context of post-secularist thinking. Paper read at the Discourse, Power, Resistance Conference 4. 21-23 March 2005. University of Plymouth. 6.

Crane, A \& Matten, D 2004. Business ethics. New York: Oxford University Press.

Douma, J 1999. Grondslagen Christelijk ethiek. Kampen: Kok.

Gabriele, E. 2011a. From the editor's desk. Journal for Healthcare, Science and Humanities, 1 (1): 11-12.

Gabriele, E. 2011b. Ethical leadership in research, healthcare, and organizational systems. Commentary and critical reflections. Journal of Research Administration, xlii (1): 88-102.

Godecharle, S, Nemery, B \& Dierickx, K 2013. Integrity training: Conflicting practices. Science, 340: 1403.

Koopman, N \& Vosloo, R 2002. Die ligtheid van die lig. Wellington: Lux Verbi BM.

Kornfeld, DS 2013. Integrity training: Misconduct's source. Science, 340, 14031404.

Lenn, DJ 2002. The globalization of business work ethics. Navigating between gentle breezes and turbulent storms. In Lategan, L and Le Roux, P (eds). Business Ethics. Bloemfontein: Tekskor. 3-15.

Mueller, PS, Hook, CC \& Fleming, KC 2004. Ethical issues in geriatrics: A guideline for clinicians. Mayo Clinic Proceedings, 79 (4): 554-562. 
Ozawa-de Silva, B, Dodson-Lavelle, B, Raison \& Negi, LT 2012. Compassion and ethics: Scientific and practical approaches to the cultivation of compassion as a foundation for ethics subjectivity and well-being. Journal of Healthcare, Science and the Humanities, Vol. 11 (2): 145-161.

Phalime, M 2014. Postmortem: The doctor who walked away. A true story. Cape Town: Tafelberg.

Robbins, SP, Bergman, R, Stagg, I \& Coulter, M 2003. Foundations of management. French Forest: Pearson Education Australia.

Roberts, D 2012. Debating the cause of health disparities. Cambridge Quarterly of Healthcare Ethics, 21: 332-341.

Rozmaryn, LM 2011. Decency, honor, integrity and the law. Journal of Hand Surgery. 1397-1402.

Schotsmans, P 2012. In goede handelen. Tielt: Lannoo.

Shaw, WH \& Barry, V 2004. Moral issues in business. Belmont: Wadsworth / Thompsons Learning.

Smit, J.H. 2000. Ethics and the technological university. In Lategan, LOK (ed.). The making of a university of technology. Bloemfontein: Technikon Free State Studies in Higher Education No 3. 144-152.

Taboada, P 2011. How do we conceive a "more compassionate" medical ethics? International Association for Hospice and Palliative Care. Available from: http:// hospicecare.com/about-iahpc/publications/ethical-issues-2/articles-of-the-month/howdo-we-conceive-a-more-compassionate-medical-ethics/ [Accessed on 2011/11/28]

Ten Have, H 2011. Bioethiek zonder grenzen. Mondialisering van gezondheid, ethiek en wetenschap. Valkhof Pers.

Thies, D 1998. Should ethics be taught in college? In Hartman, LP (ed.). Perspectives in Business Ethics. Chicago: Irwin McGraw Hill.

Vanlaere, L \& Burggraeve, R 2013. Gekken werk: kleine ondeugden voor zorgdragers. Tielt: Uitgeverij Lannoo Campus.

Woolf, SH 2012. The price of false beliefs: Unrealistic expectations as a contributor to the health care crisis. Annals of Family Medicine, 10 (6): 491-493. 